\title{
NECESSIDADES DOS FAMILIARES NA SALA DE ESPERA DE UMA UNIDADE DE TERAPIA INTENSIVA*
}

\author{
Gloriana Frizon¹, Eliane Regina Pereira do Nascimento ${ }^{2}$, Katia Cilene Godinho Bertoncello 3
}

\begin{abstract}
RESUMO: Trata-se de um estudo qualitativo que objetivou conhecer as necessidades dos familiares de pacientes internados na Unidade de Terapia Intensiva. O estudo foi realizado em um hospital geral de grande porte da região oeste de Santa Catarina, envolvendo 18 familiares que concederam entrevista; para o tratamento dos dados utilizou-se o Discurso do Sujeito Coletivo. Dos relatos surgiram dois temas: Receber informação sobre o paciente e Ter mais horários de visita. Os resultados apontaram que as informações dispensadas devem transmitir confiança e segurança e as rotinas de visita precisam ser revistas. O estudo propicia a reflexão sobre o agir da enfermagem com os familiares em unidade crítica e considera que, por meio de ações acolhedoras, os profissionais podem contribuir para o enfrentamento da família diante da hospitalização em unidade de terapia intensiva.

PALAVRAS-CHAVE: Unidades de terapia intensiva; Família; Enfermagem.

\section{NEEDS OF FAMILY MEMBERS IN THE WAITING ROOM OF AN INTENSIVE CARE} UNIT
\end{abstract}

ABSTRACT: This qualitative study aimed to investigate the needs of family members of patients hospitalized in an Intensive Care Unit. The study was undertaken in a large general hospital in the west region of Santa Catarina, involving 18 family members who granted interviews; Discourse of the Collective Subjective was used for processing the data. Two themes emerged from the accounts: Receiving information about the patient and Having more visiting hours. The results indicate that information given must convey confidence and security, and that the routine visits need to be reviewed. The study provides reflection about how Nursing acts with family members in critical care and considers that through welcoming actions the health professionals can contribute to how the family faces a member's hospitalization in an intensive care unit.

KEYWORDS: Intensive care units; Family; Nursing.

\section{NECESIDADES DE LOS FAMILIARES EN LA SALA DE ESPERA DE UNA UNIDAD DE TERAPIA INTENSIVA}

RESUMEN: Este esun estudio cualitativo cuya finalidad fue conocer las necesidades de los familiares de pacientes internados en la Unidad de Terapia Intensiva. El estudio fue realizado en un hospital general de gran porte de la región oeste de Santa Catarina, con 18 familiares que participaronde la entrevista. Para el tratamiento de los datos, fue utilizado el Discurso del Sujeto Colectivo. De los relatos,resultaron dos temas: Tener información acerca delpaciente y Más horarios disponibles para visita. Los resultados apuntaron que las informaciones deben transmitir confianza y seguridad y las rutinas de visita deben ser reevaluadas. El estudio propicía la reflexión sobre el actuar de la enfermería con los familiares en unidad crítica y considera que, por medio de acciones acojedoras, los profesionales pueden contribuir para el afrontamiento de la familia delante de la hospitalización en unidad de terapia intensiva.

PALABRAS CLAVE: Unidades de terapia intensiva; Familia; Enfermería.

\footnotetext{
*Recorte da dissertação "Os familiares na sala de espera de uma unidade de terapia intensiva: sentimentos revelados e expectativas de cuidado" apresentada ao Programa de Pós-Graduação em Enfermagem da Universidade Federal de Santa Catarina - UFSC, 2009.

${ }^{1}$ Enfermeira do Hospital Regional do Oeste. Mestre em Enfermagem. Professora do Curso de Graduação em Enfermagem da Universidade do Estado de Santa Catarina - UDESC.

${ }^{2}$ Enfermeira. Doutora em Enfermagem. Professora do Departamento e do Programa de Pós-Graduação em Enfermagem da UFSC. Coordenadora do Grupo de Estudo no Cuidado de Pessoas nas Situações Agudas de Saúde - GEASS.

${ }^{3}$ Enfermeira. Doutora em Enfermagem Fundamental. Professora do Departamento e Coordenadora do Mestrado Profissional Associado à Residência Multidisciplinar em Saúde da UFSC. Pesquisadora do GEASS.
} 


\section{INTRODUÇÃO}

A família é de vital importância nas questões referentes ao processo de saúde-doença dos seus componentes. Quando uma pessoa, por diferentes motivos, necessita hospitalizar-se numa Unidade de Terapia Intensiva (UTI), o que ocorre é sua separação dos familiares. Nesses serviços, a separação é imposta pelas circunstâncias criadas pela internação e por rotinas de visitas, muitas vezes rígidas. As informações aos familiares, geralmente, são limitadas e expressões como - aguardem um momento, não podemos atendê-los agora - são, comumente, ouvidas pelos familiares ${ }^{(1)}$.

O fato de conviver com a possibilidade da morte e da ruptura da família, diferentes sentimentos e reações ocorrem no ambiente familiar durante o período vivido. É importante ressaltar que a equipe de enfermagem deve assumir características que permitam conhecer a realidade familiar e a forma de enfrentar a hospitalização, revendo particularidades ${ }^{(2)}$. A maneira da família ver a enfermidade pode ser influenciada por fatores tais como: estágio da vida familiar, papel desempenhado por essa pessoa, implicações que o impacto da doença causa em cada um dos membros da família, e o modo como ela se organiza durante esse período. Todos esses fatores afetam diretamente o nível de estresse dos familiares ${ }^{(3)}$.

Em um estudo sobre o significado cultural do cuidado em UTI foi observado que o relacionamento da equipe de enfermagem com os familiares acontecia de modo formal, burocrático e, sobretudo, despersonalizado. O diálogo com a família era superficial; os enfermeiros, assim como os demais profissionais de enfermagem, evitavam o contato com os familiares ${ }^{(4)}$. A dificuldade de relacionamento entre a equipe de enfermagem e a família induz ao distanciamento. Esse afastamento se deve a vários fatores, os mais evidentes são relativos à falta de preparo da enfermagem frente às necessidades da família e a organização do trabalho. Para alguns enfermeiros, a dificuldade em atender a família está vinculada às especificidades de uma terapia intensiva, às próprias limitações pessoais ou da equipe de saúde e, ainda, ao modo das famílias expressarem seus sentimentos ${ }^{(5)}$.

O cuidado de enfermagem relacionado com a família na UTI vai além de consentir, ou não, a visita do familiar compreende, também, o estabelecimento de relação de confiança e de auxílio. A equipe de enfermagem tem a função de identificar as reais necessidades dos familiares, quanto mais antecipado for a interação - enfermeiro familiar - melhor será para os familiares e, consequentemente, para o paciente hospitalizado ${ }^{(4)}$.

Estudos apontam a necessidade de atender a família antes da sua entrada na UTI, para prepará-la para o encontro com o familiar doente. Na prática assistencial em ambiente crítico, mostra ser incontestável a necessidade de atender os familiares, tendo em vista seus sentimentos e fragilidades. É preocupante notar que, na maioria das vezes, o visitante é abordado de forma sutil pelos enfermeiros ${ }^{(1,4,6)}$.

Diante do contexto, foi proposto como pergunta norteadora desta pesquisa: quais as necessidades dos familiares, antes de entrarem no ambiente de terapia intensiva?

Com a vivência em UTI, acredita-se ser a sala de espera dessa unidade um espaço que precisa ser ocupado pelo enfermeiro para o atendimento ao familiar, e para responder aos seus questionamentos. Procurando minimizar a lacuna que existe nessa área foi traçado como objetivo da investigação: conhecer quais as necessidades dos familiares, antes da visita aos pacientes internados na UTI.

\section{MÉTODO}

Trata-se de uma pesquisa de abordagem qualitativa exploratória descritiva, realizada com os familiares de pacientes internados na UTI geral de um hospital público de grande porte, referência da região oeste do Estado de Santa Catarina. Os participantes do estudo foram os familiares de pacientes internados na referida UTI. Um princípio orientador da quantidade de participantes foi a saturação dos dados ou informações, isto é, mostrar até o ponto em que não é obtida informação nova, e é atingida a redundância ${ }^{(7)}$. Essa saturação no estudo ocorreu com a participação de 18 familiares.

Os critérios de inclusão foram: ter idade igual ou superior a 18 anos, ter um familiar internado na UTI, num período mínimo de 48 horas, ter relações de convívio diário com o familiar internado; e ter laços consanguíneos ou de afetividade com o paciente. O critério de exclusão foi a instabilidade emocional do familiar.

Vale ressaltar que no cotidiano da UTI, no qual o estudo foi realizado, o mais comum é a visita ser realizada pelas pessoas que compõem a família nuclear do paciente. São, principalmente, filhos e cônjuges. A escolha do membro da família que participaria da entrevista deu-se por escolha dos familiares e pelo fato de ser o visitante mais frequente. 
A entrada dos familiares na instituição ocorre, diariamente, às $12 \mathrm{~h} 45 \mathrm{~min}$. Como rotina, os visitantes aguardam, no corredor em frente à unidade, para serem chamados a fim de entrarem. É permitida a entrada de somente dois visitantes familiares do paciente, com período de permanência de 30 minutos. O chamado dos visitantes dá-se pelo nome do paciente internado e é realizado por um membro da equipe de enfermagem, previamente escalado.

A coleta de dados foi realizada com os familiares por meio de entrevista semiestruturada e relacionada às necessidades dos familiares na sala de espera da UTI. As entrevistas ocorreram nos meses de junho e julho de 2009 e, individualmente, após a aprovação do Comitê de Ética em Pesquisa com seres Humanos da Universidade Federal de Santa Catarina, parecer n. 083/09 e a assinatura do Termo de Consentimento Livre e Esclarecido.

A primeira abordagem aos familiares aconteceu na sala de espera da UTI, quando foi explicado o objetivo da pesquisa e consultados sobre o interesse em participar. Em seguida, foi agendado um horário, em comum acordo com o familiar, para a entrevista.Para a realização destas a gerência de enfermagem do hospital ofereceu uma sala próxima à UTI, sendo realizada após a visitae com duração média de 30 minutos. Cada familiar foi entrevistado uma vez e as entrevistas foram gravadas e transcritas; para preservar a privacidade dos participantes, utilizou-se, para identificação o código por numeração de ordem de execução, por exemplo: Familiar 1 (F1), Familiar 2 (F2) e, assim, sucessivamente.

Para o tratamento dos dados adotou-se três figuras metodológicas do Discurso do Sujeito Coletivo: Expressões Chaves (ECHS); as Ideias Centrais (IC) e o Discurso do Sujeito Coletivo (DSC) ${ }^{(8)}$. As ECHS são pedaços, trechos ou transcrições contínuas ou descontínuas da fala que revelam a essência do conteúdo de um dado fragmento que compõe o discurso. Devem ser destacadas pelo pesquisador, e revelam a essência do depoimento ou, mais precisamente, do conteúdo discursivo dos segmentos em que se divide o depoimento. As IC são expressões linguísticas que revelam ou descrevem de maneira sintética e precisa o sentido, ou o sentido e o tema, de cada conjunto homogêneo de ECHS e que vão dar origem ao $\mathrm{DSC}^{(8)}$.

O DSC, portanto, é uma agregação, ou soma não matemática de pedaços isolados de depoimentos, de modo a formar um todo discursivo coerente, em que cada uma das partes se reconheça como constituinte desse todo, é um discurso síntese redigido na primeira pessoa do singular e composto pela colagem das ECHS que têm a mesma $\mathrm{IC}^{(8)}$.

\section{RESULTADOS}

Dos 18 familiares que compuseram o corpus amostral, 15 eram mulheres, sendo que 9 eram filhas, duas esposas, duas mães, uma nora e uma irmã. A faixa etária dos participantes variou de 23 a 55 anos e prevaleceu o ensino primário completo como grau de instrução. A média de permanência do familiar hospitalizado foi de cinco dias. Os depoimentos dos familiares resultaram em dois temas, abaixo apresentados com respectivos IC e DSC.

\section{Tema 1. Necessidade de informação.}

IC1: Falta comunicação e as informações são divergentes.

DSC1: Falta comunicação entre a equipe, e com a família que está na sala de espera. Temos pouco contato com a equipe da UTI. Seria interessantíssimo se tivesse alguém na sala de espera que nos informasse com civilidade, que saiba conversar com as pessoas. Não tem ninguém na sala de espera para orientar. Um enfermeiro seria o melhor, pois é ele que está próximo ao paciente o tempo todo. Dentro da UTI todos os profissionais deveriam ter a mesma linguagem, tem que ser uma informação só. O familiar é como um leão que não comeu nada e ele quer um pedaço de carne, ele quer resposta para as suas angústias. Se quisermos saber alguma coisa temos que acionar a campainha e aguardar, então recebemos as informações. Dependemos deles e temos que ficar esperando, isso não é aceitável. Às vezes, torna-se difícil, porque um passa para o outro, vem um da enfermagem e pede para a gente falar com a enfermeira e essa solicita que se aguarde o médico para informar, o qual, muitas vezes, demora horas, isso quando vem dar informação. As informações ocorrem, de vez em quando, de forma diferente de um profissional para outro e, muitas vezes, não são compreensiveis. Acho que eles têm que se fazer entender com o pequeno, com o esperto, com o malandro, nós precisamos conversar. Acho que o bom profissional é aquele que consegue dialogar até com um analfabeto, ou com aquele que não entende nada. A comunicação está sendo esquecida. (F1, F4, F6, F12, F15, F17)

O DSC1 denota que o que os familiares esperam 
dos profissionais da UTI informações sobre o seu familiar hospitalizado. O discurso aponta que os familiares recebem informações, porém repassadas de maneira informal e muitas vezes desencontradas. Transparece, também, no discurso, que as informações só ocorrem se o familiar solicitar; gerando situações de desconforto para os familiares, pois se observa, além da morosidade no atendimento das informações, a falta de comprometimento dos profissionais em fornecê-las.

\section{Tema 2. Necessidade de mais horários de visita}

IC2: Ter mais horários de visitas.

DSC2: Está bom o tempo de trinta minutos para a visita, porque eu acho que visita é visita, não ficar ali todo o tempo com o paciente, porque eles têm que descansar. Acho necessário ter mais horários de visita, você entra ao meio dia e se não pode voltar no final da tarde, aí você fica a noite inteira e só vê no outro dia ao meio dia. Deveria ter um horário de visita de manhã, ao meio dia e a noite, porque aí vocêfica mais calma e não passaria a noite inteira pensando será que melhorou a ainda espera mais uma manhã inteira. Acho que o tempo de visita poderia ser, não de trinta minutos, mas de quinze, os outros quinze minutos poderia ser na parte de manhã, porque não precisa ficar muito tempo, se a gente entrar cinco minutos, já vai se saber se deu uma reagida ou não. Fico torcendo que chegue a hora de entrar lá para ver ele. (F1, F2, F5, F12, F13, F14, F18)

No DSC2, observamos a insatisfação dos familiares frente ao pouco contato com o paciente.

\section{DISCUSSÃO}

Estudos apontam que é importante que as informações sejam claras, concisas e com linguagem apropria$\mathrm{da}$, permitindo que os familiares perguntem e digam o que pensam e sentem, bem como, incentivá-los a falar sobre a situação ${ }^{(1,4,6-7)}$. A equipe da UTI deve evitar termos técnicos e jargões de difícil entendimento, porém isso não significa que devam utilizar termos incorretos ou imprecisos ${ }^{(9)}$.

Ainda com relação às informações aos familiares, há a necessidade de pessoas capacitadas para transmití-las, visando à compreensão e satisfação do familiar. Deve ser um membro da equipe que se preocupe em fornecer as informações evolutivas que traduzam confiança e segurança para quem ouve. $\mathrm{O}$ familiar se queixa, com fequência, não apenas da maneira como o profissional transmite a informação; mas, principalmente, da sua incapacidade de esclarecer suas dúvidas ${ }^{(10)}$.

A falta de informação gera ansiedade e intensa mobilização de energia, por parte da família, dependendo dos tipos de personalidades e circunstâncias, sendo a ansiedade expressa de várias maneiras, muitas vezes, negativas, agressivas e outras vezes, passivas e ausentes $^{(11)}$.

O que se constata em UTI é que o diálogo com os familiares é pontual, e pouco se vê o profissional acompanhando o momento da visita, ou presente nos momentos de maior angústia do familiar. Em alguns serviços, o horário de visitas coincide ou ocorre próximo ao horário de troca do plantão, rotina que não pode ser interrompida ${ }^{(12)}$. Este cenário, contudo, interfere de maneira negativa na comunicação da equipe com o familiar.

Com o intuito de organizar as informações dadas aos familiares, no sentido de evitar divergências, autores defendem a padronização das informações ${ }^{(13)}$, porém outros a refutam pelo risco de tornar-se mais uma rotina a ser cumprida, descaracterizando a individualidade dos familiares quanto às necessidades de informações ${ }^{(1)}$.

Um fato importante a ser registrado é o de que na UTI, onde o estudo foi realizado, a equipe médica, mesmo tendo conhecimento de uma normativa administrativa na qual o plantonista deverá fornecer informações do paciente para o familiar no momento da visita; isso, na prática, não ocorre. As informações, nesse serviço, são fornecidas pelos enfermeiros, principalmente, quando os familiares as solicitam.

Estudos apontam, também, as dificuldades dos familiares em ter acesso a quem detém as informações. O ideal seria existir uma pessoa, devidamente, treinada; que soubesse de cada paciente, para transmitir as informações necessárias. A presença, portanto, do enfermeiro junto aos familiares deve possibilitar a troca de informações da evolução do paciente, por meio de uma comunicação efetiva, contribuindo para a identificação de dificuldades dos familiares e oferecendo o apoio necessário ${ }^{(14)}$. O discurso dos participantes também revela a necessidade de ter um profissional na sala de espera para realizar as orientações e repassar informações sobre os pacientes e a unidade, atendendo às necessidades dos familiares. Nesse momento, é de extrema importância a atuação do enfermeiro com a função de orientação, além do papel que assume 
como intermediador entre o paciente e sua família, num ambiente e condição estressantes para ambos. A orientação e a informação, em geral, tranquilizam o indivíduo, pois quando ele tem suas dúvidas esclarecidas, sente-se mais seguro e confiante ${ }^{(1,4)}$.

Um dos maiores desafios para a equipe da UTI, porém, é atender aos anseios que cada membro da família demanda, pois eles variam de um indivíduo para outro e a enfermeira possui um tempo escasso ${ }^{(4)}$. Acredita-se, no entanto, que o familiar pode ser melhor acompanhado por uma equipe de apoio, de forma proativa, ou seja, tentando identificar e monitorar famílias; tirando suas dúvidas, dando explicações e avaliando suas dificuldades antes que os problemas tornem-se maiores tanto para a família, como também para a equipe da UTI ${ }^{(15)}$. Frequentemente as necessidades dos familiares são ignoradas ou esquecidas devido ao fator tempo, a falta de conhecimento em como lidar com os membros da família e a falta de compreensão de suas reais necessidades. Geralmente, o contato da equipe com os familiares é breve e, quando isso ocorre, os assuntos discutidos são os problemas vistos pela enfermeira e não pelo familiar. Os regulamentos que permitem a visita de apenas uma pessoa, frequentemente, reduzem o número de vezes que os membros da família terão contato com a mesma enfermeira em um $\operatorname{dia}^{(4)}$ dificultando a aproximação e o vínculo.

A falta de informação e a dúvida frente à evolução da situação clínica constituem importante fator de angústia em pacientes e seus familiares. A dúvida, normalmente, causa preocupação e ansiedade nos membros da família, que esperam angustiados o momento da visita, esses desejam estar com o seu familiar doente, de ver o ente querido e, de preferência, ouvir notícias boas. Nesse caso, entende-se por boas notícias informações relacionadas à melhora do estado clínico do paciente, ao aumento da probabilidade de cura e à diminuição do risco de morte. Agir de forma adequada, com palavras sinceras, simples e condizentes com o nível sociocultural dos familiares, é um importante requisito para a qualidade do cuidado ${ }^{(5,16)}$.

O fato da família estar informada sobre o estado de saúde do paciente, como ele irá encontrá-lo, o porquê dos dispositivos nele instalado, dentre outras informações, e de poder perceber nos profissionais de enfermagem a preocupação com o seu bem-estar e o estar melhor, disponíveis em ouvir seus sentimentos e necessidades; poderá influenciar, positivamente, no seu enfrentamento à doença aguda grave e a hospitalização em uma UTI ${ }^{(1)}$.
No DSC2, a situação da internação na UTI torna-se mais difícil para os familiares quando estes se deparam com um serviço em que as rotinas de visita são impostas, com horários rígidos, tempo de visita muito curto e número restrito de visitantes por doente ${ }^{(1)}$. A Política Nacional de Atenção ao Paciente Crítico; recentemente, instituída pelo Ministério da Saúde, reconhece a importância do atendimento humanizado aos pacientes e familiares e determina, por exemplo, que as UTI devam oferecer, no mínimo, três visitas diárias programadas aos familiares ${ }^{(17)}$.

Esta importante necessidade do familiar afetada não poder estar mais tempo junto ao seu ente querido, deixa-o muito desconfortável e com medo. Isso decore do fato daquele estar em uma unidade crítica, onde as pessoas correm risco de vida constante. Também, relaciona-se ao curto tempo de visita e ao fato de, ao estarem ausentes, o pior acontecer com o familiar. Isso gera um sentimento de impotência frente a não saber o que fazer e para quem reclamar.

O membro da família concebe que, 0 ao entrar na UTI, o seu ente querido já não possui mais esperança de vida. Mesmo assim, o medo do estado do paciente e da cena que irão ver ao entrarem, deixam o familiar perdido por não conhecer os rituais desse setor, e aflito para falar com alguém da equipe, a fim de obter informação sobre o enfermo.

É preciso, no entanto, aceitar e incorporar a ideia de ver os familiares não só como fiscais implacáveis que aborrecem a todo instante, mas sim como importantes para a recuperação do paciente e que, também, precisam de cuidados de acordo com suas necessidades ${ }^{(6)}$.

A comum inflexibilidade na de rotina de visita, mesmo se tratando de uma UTI, não é mais recomendada, pois o acolhimento, não só ao paciente, mas também ao seu familiar, é uma necessidade urgente, e que se reflete de forma positiva para o bem-estar de ambos, quando bem aplicado; planejar maior atenção ao visitante, antes deste entrar em um ambiente crítico, é um grande desafio. Mesmo conscientes de que o local de estudo não tem estrutura física adequada, como uma sala de espera exclusiva para acomodação e atendimento aos familiares; sugere-se aos enfermeiros tomarem a iniciativa, junto com outros profissionais e apresentarem uma proposta de ajuste físico, com a finalidade de solucionar o problema.

É recomendado, portanto, estabelecer um vínculo enfermagem e família, pois constitui uma forma de amenizar o isolamento social que a hospitalização impõe. Bem como, auxiliar na reestruturação biopsicosocial da 
família. Agir perante a família de forma a ajudá-la em seus anseios, não deve dificultar o cotidiano do trabalho da equipe de enfermagem que, geralmente, alega falta de tempo para atender os familiares ${ }^{(1)}$.

Entre os fatores que dificultam o processo de integração e vínculo, está o desconhecimento por parte da equipe de enfermagem frente ao modo de ser e de perceber dos familiares ${ }^{(4)}$. Está em poder da enfermagem, profissão que enfatiza o tratamento personalizado e holístico, realizar as ações que poderiam viabilizar o entendimento e a compreensão da internação em UTI, tanto por parte dos sujeitos nela internados quanto de seus familiares. É essencial o acompanhamento do familiar, pela equipe de enfermagem, durante a internação, principalmente, no momento da primeira visita; para prestar-lhe apoio e orientação no que for necessário, além do que, essa atitude poderá minimizar a visão de unidade hostil ${ }^{(18)}$.

Com relação às normas de visita, estudos retratam que, de acordo com os padrões institucionalizados de visitas rápidas e pontuais, são poucas as possibilidades dos familiares visitarem com mais frequência seus familiares. É preciso que se priorize a reformulação da rotina do horário de visita e tempo de permanência dos familiares junto aos enfermos da $\mathrm{UTI}^{(6)}$.

A necessidade verbalizada pelos familiares, de ter mais horários de visita na UTI, permite fazer uma leitura de que o distanciamento prolongado entre uma visita $\mathrm{e}$ outra gera sentimentos desagradáveis e, até mesmo, uma cobrança maior de atenção aos profissionais de enfermagem. Estes estão mais visíveis durante a visita e são responsabilizados pelo rigor das normas estabelecidas, podendo, erroneamente, ter sua imagem distorcida negativamente devido ao distanciamento físico e verbal.

Para tanto, sugere-se rever a possibilidade de flexibilização do horário e do número de visitantes da UTI, por acreditar ser essa uma estratégia de acolhimento.

Outra estratégia, no entanto, de acolhimento e não menos importante é sugerida: a de organizar um folheto informativo sobre a UTI, e distribuí-lo, antes de o familiar entrar, pela primeira vez, nesse ambiente desconhecido. Considerando que o conteúdo será destinado a leigos, ele deverá conter informações curtas, com linguagem simples, letras grandes; utilizando de figuras coloridas, e informando os números dos telefones da UTI e da assistente social, para obter informações diárias sobre o estado de saúde de seu familiar, os horários e condutas para visitantes. Espera-se que esse cuidado proporcione ao familiar mais segurança e informação.
Ressalta-se, todavia que reorganizar o cenário de trabalho cujas ações ainda estão centradas no modelo tecnicista e voltadas; quase que exclusivamente, para a pessoa internada, desconsiderando o seu familiar, é um trabalho árduo e um desafio para a enfermagem em especial a que atua em unidades de alta complexidade, como as UTI.

\section{CONSIDERAÇÕES FINAIS}

Os DSC revelaram um emaranhado de necessidades com os quais os familiares convivem no seu dia-a-dia, durante a hospitalização de seu ente querido na UTI e, em especial, no momento que antecede à visita. Considera-se que essas necessidades seriam minimizadas se o espaço da sala de espera fosse ocupado por multiprofissionais da saúde, em especial enfermeiros. Esses têm a possibilidade de oferecer acolhimento aos familiares, preparando-os para a visita, escutando-os, esclarecendo dúvidas, atendendo suas necessidades de informação. Proporcionando-lhes, também, mais tempo junto ao familiar, dentro do contexto do ambiente crítico, com toda a sua tecnologia e linguagem específica.

Entende-se, portanto, que isso requer além de uma estrutura física, que ofereça conforto e privacidade aos familiares, sensibilização, preparo, reconhecimento e valorização das expectativas e necessidades dos familiares, não só pela equipe de enfermagem, mas também pelos gestores e demais profissionais que atuam em unidades críticas. Contudo, o estudo retrata a necessidade de um agir mais acolhedor da enfermagem com os familiares na unidade crítica. $\mathrm{O}$ acolhimento à família necessita de inserção, como elemento do cuidado, por meio de ações acolhedoras, ajudando-os a enfrentarem a hospitalização na UTI. As informações devem transmitir, aos familiares, confiança e segurança. As rotinas de visita precisam ser revistas visando a um cuidado mais humanizado aos pacientes e aos familiares.

\section{REFERÊNCIAS}

1. Frizon G, Nascimento ERP, Bertoncello KCG, Martins JJ. Familiares na sala de espera de uma unidade de terapia intensiva: sentimentos revelados. Rev Gaúcha Enferm. [Internet] 2011;32(1) [acesso em 02 fev 2012]. Disponível: http://www.scielo.br/scielo.php?script=sci_ arttext\&pid=S1983-14472011000100009\&lng=pt\&nrm =iso ISSN 1983-1447. http://dx.doi.org/10.1590/S198314472011000100009

2. Salicio DMB, Gaiva MAM. O significado de humanização da assistência para enfermeiros que atuam em UTI. Rev. 
Eletr. Enf. [Internet] 2006;8(3) [acesso em 02 fev 2012]. Disponível: http://www.fen.ufg.br/revista/revista8 3/ v8n3a08.htm. ISSN 1518-1944.

3. Soares M. Cuidando da família de pacientes em situação de terminalidade internados na unidade de terapia intensiva. Rev Bras Ter Intensiva. [Internet] 2007;19(4) [acesso em 07 fev 2011]. Disponível: http:// www.scielo.br/scielo.php?script=sci_arttext\&pid=S0103507X2007000400013\&lng=en. http://dx.doi.org/10.1590/ S0103-507X2007000400013. ISSN 0103-507X.

4. Maruiti MR, Galdeano LE. Necessidades de familiares de pacientes internados em unidade de cuidados intensivos. Acta Paul. Enferm. [Internet] 2007;20(1) [acesso em 02 fev 2012]. Disponível: http://www. scielo.br/scielo.php?script=sci_arttext\&pid=S0103$21002007000100007 \& \operatorname{lng}=$ en $\& \mathrm{nrm}=$ iso. ISSN 1982-0194. http://dx.doi.org/10.1590/S010321002007000100007. ISSN 1982-0194.

5. Almeida AS, Aragão NRO, Moura E, Lima GC, Hora EC, Silva LASM. Sentimentos dos familiares em relação ao paciente internado em unidade de terapia intensiva. Rev Bras Enferm. [Internet] 2009;62(6) [acesso em 07 fev 2011]. Disponível: http://www. scielo.br/scielo.php?script=sci_arttext\&pid=S003471672009000600007\&lng=en. http://dx.doi.org/10.1590/ S0034-71672009000600007. ISSN 0034-7167.

6. Gotardo GIB, Silva CA. O cuidado dispensado aos familiares na unidade de terapia intensiva. Rev. enferm. UERJ. [Internet] 2005;13(2) [acesso em $02 \mathrm{fev}$ 2012]. Disponível: http://www.arca.fiocruz.br/handle/ icict/184. ISSN 0104-3552.

7. Minayo MCS. O desafio do conhecimento: pesquisa qualitativa em saúde. São Paulo: Hucitec-Abrasco; 2010.

8. Lefèvre F, Lefèvre AMC. O discurso do sujeito coletivo: uma nova abordagem metodológica em pesquisa qualitativa. Caxias do Sul: EDUCS; 2005.

9. Nascimento AZ, Ribeiro G, Bernardino E, Oliveira ES. Limites e possibilidades da permanência de familiares em unidade de terapia intensiva. Cogitare enferm. [Internet] 2007;12(4) [acesso em 07 fev 2011]. Disponível: http://ojs.c3sl.ufpr.br/ojs2/index.php/cogitare/article/ view/10069. ISSN Eletrônico: 2176-9133.

10. Barbosa EMA, Brasil VV. Boletim informativo em UTI: percepção de familiares e profissionais de saúde. Rev. Eletr. Enf. [Internet] 2007;9(2) [acesso em $02 \mathrm{fev}$ 2012]. Disponível: http://www.fen.ufg.br/revista/v10/ n1/v10n1a29.htm. ISSN 1518-1944.
11. Ruedell LM, Beck CLC, Silva RM da, Lisboa RL, Prochnow A, Prestes FC. Relações interpessoais entre profissionais de enfermagem e familiares em unidade de tratamento intensivo: estudo bibliográfico. Cogitare enferm. [Internet] 2010;15(1) [acesso em 07 fev 2011]. Disponível: http://ojs.c3sl.ufpr.br/ojs2/index.php/cogitare/ article/viewArticle/17186. ISSN Eletrônico: 2176-9133.

12. Bettinelli LA, Rosa J, Erdmann AL. Internação em unidade de terapia intensiva: experiência de familiares. Rev Gaúcha Enferm. [Internet] 2007;28(3) [acesso em 07 fev 2011]. Disponível:http://seer.ufrgs.br/RevistaGauchadeEnfermagem/ article/view/4688. ISSN 0102-6933.

13. Mezzaroba RM, Freitas VM de, Kochla KRA. O cuidado de enfermagem ao paciente crítico na percepção da família. Cogitare enferm. [Internet] 2009;14(3) [acesso em 07 fev 2011]. Disponível: http://bases.bireme.br/cgi-bin/ wxislind.exe/iah/online/?IsisScript=iah/iah.xis\&src $=$ goog le\&base $=$ LILACS\&lang $=p \&$ nextAction $=\operatorname{lnk\& \text {exprSearc}}$ h=568396\&indexSearch=ID. ISSN Eletrônico: 2176-9133.

14. Inaba LC, Silva MJP, Telles SCR. Paciente crítico e comunicação: visão de familiares sobre sua adequação pela equipe de enfermagem. Rev Esc Enferm USP. [Internet] 2005;39(4) [acesso em 02 fev 2012]. Disponível: http://www. scielo.br/pdf/reeusp/v39n4/07.pdf. ISSN 1980-220X.

15. Luz CF, Melnik MG, Bernardino E, Oliveira ES. Compreendendo as restrições dos técnicos de enfermagem sobre a permanência de acompanhantes em unidade de terapia intensiva aberta. Texto Contexto Enferm. [Internet] 2009;18(2) [acesso em 07 fev 2011]. Disponível: http://www.scielo.br/pdf/tce/v18n2/14.pdf. http://dx.doi.org/10.1590/S0104-07072009000200014.

16. Silva L, Bocchi SCM, Bousso RS. O papel da solidariedade desempenhado por familiares visitantes e acompanhantes de adultos e idosos hospitalizados. Texto Contexto Enferm. [Internet] 2008;17(2) [acesso em $02 \mathrm{fev}$ 2012]. Disponível: http://www.scielo.br/pdf/tce/v17n2/11. http://dx.doi.org/10.1590/S0104-07072008000200011.

17. Almeida AS, Aragão NRO, Moura E, Lima GC, Hora EC, Silva LASM. Sentimentos dos familiares em relação aos pacientes internados na unidade de terapia intensiva. Rev Bras Enferm. [Internet] 2009;62(6) [acesso em 07 fev 2011]. Disponível: http://www.scielo. br/pdf/reben/v62n6/a07v62n6.pdf. ISSN 0034-7167.

18. Bicalho CS, Lacerda MR, Catafesta F. Refletindo sobre quem é o cuidador familiar. Cogitare enferm. [Internet] 2008;13(1) [acesso em 02 fev 2012]. Disponível: http:// ojs.c3sl.ufpr.br/ojs-2.2.4/index.php/cogitare/article/ viewArticle/11972. ISSN Eletrônico: 2176-9133. 